\title{
Game Design as an Autonomous Research Subject
}

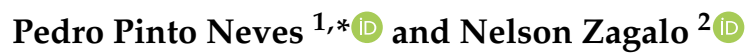 \\ 1 HEI-Lab, Department of Film and Media Arts, Lusófona University, 1749-024 Lisbon, Portugal \\ 2 DigiMedia, Department of Communication and Art, University of Aveiro, 3810-193 Aveiro, Portugal; \\ nzagalo@ua.pt \\ * Correspondence: pedro.neves@ulusofona.pt
}

check for

updates

Citation: Neves, P.P.; Zagalo, N.

Game Design as an Autonomous Research Subject. Information 2021, 12, 367. https://doi.org/10.3390/ info12090367

Academic Editors: Gabriele Gianini and Christo Dichev

Received: 19 July 2021

Accepted: 8 September 2021

Published: 10 September 2021

Publisher's Note: MDPI stays neutral with regard to jurisdictional claims in published maps and institutional affiliations.

Copyright: (c) 2021 by the authors. Licensee MDPI, Basel, Switzerland. This article is an open access article distributed under the terms and conditions of the Creative Commons Attribution (CC BY) license (https:// creativecommons.org/licenses/by/ $4.0 /)$.

\begin{abstract}
This paper examines the methods and systems of game design from the standpoint of existing method proposals failing to establish a common basis for systematizing design knowledge, which this paper aims to help resolve. Game design has often been subsumed by game development and associated disciplines, and game design methodology has often been subsumed by game analysis. This paper reviews related work in defining game design as an autonomous research subject and then divides the methods and systems of game design into complementary methods and core methods, with only the latter, consisting chiefly of design patterns, attempting to systematize how game design knowledge is generated. Seminal game patterns have been descriptive rather than -prescriptive and so have failed to find the requisite practitioner adoption to fulfill their role as a living method. One recent pattern approach has sought to resolve this issue by promoting pattern usage generally over the adoption of a particular language. This paper outlines an alternate and possibly complementary approach of a novel, practical basis for game design literacy for helping core methods work as a basis for systematizing game design knowledge. The proposed basis sacrifices descriptiveness to prescriptiveness to shape methods in that direction.
\end{abstract}

Keywords: game design methods; game design literacy; game design patterns; game design notations; game design tools

\section{Introduction}

One of the most salient features of games as an object of study and a field of practice is their interdisciplinarity and multimodality [1] (p. 89). Another salient feature is their particular nature as a kind of second-order design [2] (p. 171), which, to a certain extent, naturally turns games into black-boxes in terms of the processes by which games produce their particular effects on their players. All of this has left game design in an awkward methodological position.

Given the systemic and self-motivated nature of play in games, they beg for a formal common design vocabulary, such as general design patterns or similar, with sufficiently wide recognition to support the systematic advancement of game design knowledge across the entire field of game design. If not a common vocabulary, games at least need a common basis for the systematization of design knowledge. Game design as a discipline requires some form of core methodology, even though specialized methodology for more narrow purposes is available and in use. There is currently no system for general methodological support with wide enough recognition to perform this role. A game design method can only deliver on the benefits of a general vocabulary if it is used by a sufficient number of practitioners or, at the very least, sufficiently recognizable to their practice. The common ground for game design work, as distinguishable from game development, is the use of iteration practices, design documentation (such as game design documents, spreadsheets, and flowcharts for plotting out game play progression), and game analytics. The use of AI-driven game design annotation and diagramming tools and game notations is still 
residual and fragmentary. The same goes for the use of game design patterns as a basis for systematizing game design knowledge.

In discussing game design methods, a distinction needs to be made between game development and game design. The first refers to the production of the game as a digital or analog artifact: the technological, artistic, and technical work in achieving a finished playable product. The latter refers to what a particular game is as a game. Game design refers to both an aspect of every game and the disciplinary field concerned with that aspect.

A discussion of game design methodology further requires a distinction to be made between game design and game analytics. Game analytics model player behavior and preferences. Game analytics can inform and guide game design but are not the same as game design and cannot replace the game design for creating original games. Player satisfaction models such as BrainHex [3] can help define very broad targets for game design, but defining what the design needs to achieve is different from helping the design get there. Games need to offer resistance to their players [4] (pp. 11-12) and need to provide them something new to learn as part of the pleasure of play [5] (p. 37). There is only so much that can be done by fitting the new game to existing trends, preferences, or game profiles [6] before game creators are forced to take a chance with original game design work, if nothing else to balance play in the new game.

Taking the digital games industry as an example, methods in digital game development are in heavy use and have become highly sophisticated. Twenty years ago, many of the methods used for digital game development were cribbed from other industries, creating certain issues while solving others. This was the case with Scrum [7], for instance. Since then, software lifecycle methods have been adapted for use in game development and have enjoyed a degree of success [8]. The same goes for game creation and production tools, pipeline tools, art asset creation, and animation techniques. User experience (UX) development is a well-developed industry within the games industry [9], and the professional fields of game analytics and user research (UR) have matched the industry's growth and diversification [10]. Meanwhile, game design largely continues to make do with rules of thumb, loosely codified best practices, game genre conventions, and leaning on user feedback and player community relations even more than it already needs to [11]. Game design iteration, proposed for instance by Fullerton [12], is relevant as a general orientation for game design practice but has been pressed into service into what comes closest to a general method, as observed by Neil [13].

The absence of a general game design method in wide adoption is keenly felt, though not often directly pointed out. Although game creation will always carry a degree of uncertainty as a characteristic of cultural industries, game creation remains an indelibly risky proposition beyond this intrinsic risk. The natural characteristics of games present a number of possibilities for serious applications. Games for learning and games for health have made strides in the past 20 years, but serious games are not in as widespread use in these fields as their potential would suggest due to the uncertainty in designing games [14] (p. 638) and the large number of iterations and dead-ends required even by successful designs. A general method or at least a common basis for systematizing design knowledge could make game creation a more manageable proposition for serious applications and lead to a higher rate of game production and better games. In turn, more widespread use of serious games could help deliver on their benefits. The absence of a general method is also felt in the games industry and in the relationship between games, culture, and society. The digital games industry is particularly problematic with regards to pervasive issues such as crunchtime, defining project scope, incentive structures, and gender equality [15]. The volatile, uncertain nature of game creation as exacerbated by an absent general method contributes to these persistent problems and also to the warping of audience expectations and of the sense of a game as a value proposition. In this view, the absent general method and its effect on a basic literacy of game design have contributed to a deformation of the relationship between developers and game audiences and to toxicity and exclusion in gaming cultures. 
Game design methods do not emerge fully formed as a body of design solutions ready to be used in game design work; the body of method needs to be filled out. A game design method comprises not only the design solutions themselves but also the process of harvesting and systematizing solutions from finished game designs and particularly from ongoing game design work. A static body of method would fail to usefully reflect the procedural nature of games themselves and the iterative, experimental nature of game design work. A method being in use means not only that the method is being used to solve design problems and devise original games but also that the body of the method is being expanded through practice. A game design method can only deliver on its benefits if it gets picked up by a sufficient number of practitioners and the body of solutions in the method keeps expanding, as opposed to being static.

Proposals for the development of general game design methods gathered the most interest from 1999 to 2006 [16-19]. These proposals did not necessarily originate the idea of formal methods for game design, but they argued for it clearly, defined the requisite scope and depth, and took the first steps in filling out method corpora. The initial body of solutions in each method was meant to proof the method, help explain the method, and teach practitioners how to employ the method in design work and in adding to its body of solutions. The idea was for this initial body of solutions to undergo accelerated growth through method adoption and being put into practice until there were enough solutions in the method to let it work as a general design vocabulary. These method proposals failed to come into use as a general vocabulary [11]. Formal methods never completely went away, but interest waned. Since then, method proposals on the part of academic researchers have been more likely to variously pertain to specific aspects of games such as for instance motivation [20], level design [21] in particular genres, or sound [22] as opposed to a general method, or to be integrated with other disciplinary concerns, such as learning [23], analytics [24], or artificial intelligence [25]. There has been some interest in general methods on the part of the games industry, such as Ubisoft's rational design [26], and academia has occasionally been returning to the idea of a general method, but game methodology remains fragmentary.

The article is organized as follows. Section 2 examines related work to situate the aims and scope of this paper. Section 3 examines examples of complementary methods, that is, existing method elements such as books, notations, and frameworks that are relevant for game design but do not fulfill the core role of a common basis for systematizing design knowledge. Section 4 looks at core method proposals, that is, attempts to define a common basis for systematizing design knowledge, such as design patterns, and looks at the issue of basic game design literacy. Section 5 proposes a foundation for a practical basic literacy of game design as a means towards effective (more suitable for widespread adoption) future methodological development. The paper's main contribution of a game design principle that can meet the requirements for encouraging the adoption of a formal game design methodology can be found in this section. Section 6 concludes by discussing the methodological needs of games going forward and future challenges in consolidating game design methodology together with game design literacy and basic game design research.

\section{Related Work}

This paper argues that there is a gap in methodological support for game design, traces the nature of this gap by reviewing some of the better-known game design methods, highlights certain obstacles to game design practice resulting from the gap, and proposes a prescriptive foundational game design principle that can help improve the situation. The problem is essentially that formal thinking on games is still dominated by descriptive knowledge and game analysis, as framed by the discipline of game studies, to the detriment of prescriptive knowledge and game design methodology. This in turncreates a gap in the advancement of a certain kind of method This paper proposes a distinction between core methods and complementary methods in game design to define this gap. The obstacles to game design practice resulting from the gap are the lack of a common basis for 
systematizing game design knowledge and can also extend to added difficulties in teaching game design as well as discouraging advances in game design and more ubiquitous serious game development. The game design principle in this paper is meant to help overcome these obstacles by tackling the prescriptivity issue. Related work in the context of this paper is research that has traced the relative closing off of games research through certain aspects of game studies and proposed exits to this situation, much like this paper. Examining this research situates this paper's scope and contributions.

Despite being high-level, the game design principle proposed in Section 5 of this paper has the relatively modest goals of aiding in interdisciplinary serious game development and in game design teaching and of encouraging more generalized adoption of game design methods. This, in turn, affirms game design as an autonomous research subject. Some examples of related work have far greater scope and ambition, namely Deterding's program for redressing the interdisciplinarity of games research [27] and Klabbers' program for game science [28]. Cardona-Rivera [29] seeks predictive capabilities in the formal modeling of the game design process through computational science, which is an advanced contribution. This paper instead favors a "back-to-basics" approach of reviewing examples of "classic" sources of game methods in their own terms to tackle a longstanding issue of game design that begged for a much earlier resolution. Related work traces roughly the same issue as our paper but at a far larger disciplinary, interdisciplinary, or metadisciplinary scale and offers commensurate, comprehensive solutions that are arguably less immediately applicable or rather require wider efforts. Our proposal is complementary to these wider efforts.

This paper aims to contribute to games breaking out of descriptive thinking, which elides game design somewhat. This is not a strictly novel perspective; the paper's novel contributions are in how this issue is framed and in the solution that is proposed given this framing. The most obvious way of reasserting game design perhaps begins with the exploration of the relationship between game design and design research. This has been done, for instance, by Kuittinen and Holopainen [30] and by Kultima [31], as well as by Deterding [27] and by Klabbers [28] as part of larger disciplinary redirection programs, and by Cardona-Rivera in contributing to a game design science discipline [29].

In a 2009 paper, Kuittinen and Holopainen carefully review the most influential conceptions and models of design as an activity, provide examples of how their components can map to game design work, and proceed to review six influential game design books in how they consider these components. These authors conclude that in these books overall, "game design is heavily governed by the object of the design, games" and "the multitude of elements that can be used to construct games", with insufficient attention paid to the activity of game design, where this is not adequately handled by the "stage models" and "iterative spirals" in these books [30] (p. 7). This is comparable to the review of methods and the discussion of descriptive and prescriptive thinking in this paper, with some of the same books being analyzed. However, this paper considers game methods in terms of core and complementary methods, more in relation to themselves than in relation to broader conceptions of design. This is done in a narrower scope of proposing a game design principle for use in game design work, whereas Kuittinen and Holopainen propose changes in how game design is studied, with design-as-activity models and a situated understanding of game design. Nevertheless, their aim is to "open up new possibilities of improving the methodologies of game design" [30] (p. 7), much like our paper.

In a 2015 paper, Kultima draws from multiple sources, including a literature review, existing systematic literature reviews, and her own fieldwork with developer communities to assert that "it is typical that notions of "design" and "design research" are not explicitly reflected on the research papers within the academic field of game research", and recommends emphasis "on design research as a theoretical basis" [31]. This is in line with the aims of this paper of emphasizing autonomy for game design, although again a recommendation is made in terms of shifting a theoretical basis rather than introducing a design principle. 
In a 2017 paper, Deterding draws from an anthropological approach to the community's discourse and scientometric studies to situate the field of game studies in the context of a broader field of games research and to evaluate them in relation to a taxonomy of interdisciplinarity, asserting that "game studies have sown the seeds of their own contraction into a narrow multidisciplinary field" [27] (p. 2). In the broadest sense, the reviews in Sections 3 and 4 of this paper and Deterding's 2017 paper both find a tendency in games research to close itself off in describing games over prescribing to game design and go on to propose ways of redressing the issue. However, there is a difference in scope and focus. Our paper's review to find a gap to be filled has a more modest scope of classifying game methods on their own terms. Deterding's paper is a diagnostic of fragmentation at the scale of an entire interdiscipline [27] (p. 12), where there is a reality of games research, in which fields such as human-computer interaction (HCI) and communication research intervene as much as game studies, and then there is how the game studies community sees itself and games. This impasse creates obstacles to delivering on the real potential of interdisciplinarity in games research, and Deterding proposes a number of exits to this impasse, which include instituting "game studies as game design studies and education around applied games and play", as well as focusing on "epistemic boundary objects" for joint-study by the interdiscipline of games research [27] (p. 18). Deterding's 2017 paper shows that there is already a systematic way of making sense of game design, but also that it is not being fully actualized as interdisciplinary inquiry in games research, owing to the impasse with game studies. In relation to Deterding's findings, our paper aims to provide a design principle that can contribute to this actualization.

Compared to our design principle in Section 5, Deterding's solutions are of a different scope altogether, in that they include degree and academic job policies and disciplinary realignment. We aim for a solution that operates in a narrower, complementary scope since it takes the form of a design principle that can be readily employed in games teaching and serious game development.

A 2018 paper by Klabbers is even more ambitious than Deterding's 2017 paper, defining game science instead of merely games research, in a metadisciplinary [28] (p. 210) rather than interdisciplinary perspective, delving deeper into considerations of the philosophy of science. Our paper highlights how games, as a field of research and as a field of practice, lack a converged-upon methodology. Klabbers' paper highlights how the possibility of this convergence is already available and offers a comprehensive program for its actualization by balancing analytical and design science and by considering a typology for the relationship between designer and player [28] (pp. 238-241). Klabbers furthermore discusses the implementation of his solution, for instance, at the level of how to fund research by converging cross-disciplinary efforts in game centers [28] (p. 209). Besides the scale and scope of solutions, the framing in Klabbers' 2018 paper is markedly different from that of our paper, making careful considerations of what types and reach of knowledge apply in his vast category of game science.

It should be noted that Klabbers is concerned with "professional gaming" [28] (p. 236), which might be otherwise termed serious games, a term that Klabbers criticizes in its lack of rigor alongside gamification (pp. 230-232). Klabbers' contribution is defining a paradigm of game science oriented toward this professional gaming, where this paradigm has the advantage of "independence of the instrumentality of games", and to which the "methodology of game science should connect", with a goal of "developing systematic ways of teaching and learning game design that is responsive to societal needs" [28] (p. 235). In focusing on professional gaming, Klabbers' paper also folds the field of simulation and gaming into his vast game science, together with fields closer to, for instance, Deterding's understanding of game research [27], as a matter of course, where this can be startling given more traditional delimitations of games as a research subject. Klabbers criticizes game design's focus on what he terms design-in-the-small, the game itself, over "goals, the context of use, and target audiences", which is the design-in-thelarge of his professional games, and which he deems more important [28] (p. 236). Where 
Klabbers' vast metadisciplinary program demands that design-in-the-small adequately serve design-in-the-large, our paper seeks to highlight how design-in-the-small is not quite ready for this task and means to contribute with a design principle that can help design-in-the-small become ready for the task.

Where Deterding's [27] and Klabbers' [28] papers address the lack of a systematic way of making sense of game design and of a converged-upon methodology, respectively, and do so with larger-scope solutions, a 2020 paper by Cardona-Rivera [29] arguably tackles both of these issues with a smaller-scope solution. Cardona-Rivera has developed a computational model that can be applied to "designed games" to predict their effects "on the people that will play them" [29] (p. 2), where this author has already employed it to formally model pathfinding as a game design task. The goal is an AI-powered approach to the situated study of game design as a process of abstraction, as "part of a game design science discipline, in which game design is the object of study" [29] (p. 2). This research is broadly complementary to our paper in the sense that it affirms game design as an autonomous research subject and is heavily invested in a situated perspective. However, our goal is a simpler design principle that can help design work and method development, in a sense making game design more parsable to humans, and not the formal modeling of game design as a process, which is about making game design parsable to humans by first making it parsable for computers, albeit in a "human-centered" meaning for computational science [29] (p. 7).

In this paper, we make the argument that game design, as research and as practice, is not without advanced methods, but that there is a gap of a less advanced formulation that should have already dealt with longstanding method issues. We review examples of classic method sources with a "back-to-basics" approach to arrive at such a formulation. Related work [27-31] broadly resembles our efforts in privileging situatedness and affirming game design as an autonomous research subject, but this more sophisticated and largerscope related work has not yet delivered on benefits such as method adoption and the removal of obstacles in serious games and in teaching game design. Our paper is therefore complementary to these approaches, contributing to the same ends along different lines and in a different scope.

\section{Complementary Methods}

We divide game methodology into complementary methods and core methods. Complementary methods help analyze game designs (game design books, frameworks) or organize game design work (notations, diagramming tools); they comparatively do less for the actual act of designing, and so they cannot replace core methods. Core methods are described in Section 4 and were attempts to establish a common basis for systematizing game design knowledge. We contend that the methodological problem in game design is due to complementary methods not being able to provide full methodological support on their own and proposed core methods never gaining widespread recognition. Another relevant issue is the difference between how to design games and the study of games, which may have harmed the advancement of methodology. This is compatible with the examination by Perez [32] of the relationship between game studies and design methods from the standpoint of design research.

The difference between core methods and complementary methods and between the study of games and game methods is relevant for the aims of this paper for three reasons. The first reason is that this helps situate game design methods, which are the subject of this paper. The second reason is that given the body of already-proposed theory constructs for game design, models, frameworks, game design books, patterns, it might appear that game design methodology is equipped to meet the needs of game design as a field of practice. This is not the case because it would require more successful core methods. The third reason is that this paper aims to contribute with a theory construct (a way of thinking about game design) that specifically counteracts an imbalance between descriptiveness 
and prescriptiveness in formal game design thinking. Situating this intended contribution requires an overview of the imbalance.

Games can be studied as artifacts, as activities, and in their relationship with players and in the cultural contexts for game usage, particularly in the dedicated disciplinary field of game studies, which is transdisciplinary but fundamentally rooted in the humanities, but also by a number of other fields, in a multiplicity of perspectives. The study of games also extends to the study of game development and game design: for instance, developer cultures or game markets. There has been interest in the definition of game, but not in a way that decisively helps game design methodology.

Game studies refers to the study of games and play as a field of research in its own right as opposed to games being subsumed in other objects of study. This field had to resist colonization attempts by other fields [33]. Twenty years ago, game studies managed to establish themselves in specialized journals and conferences, and the field showed great promise in fully accounting for games and play and perhaps even influencing the industry [33]. This promise has not been delivered. Game studies are not dedicated to the study and development of game design methodology, though they should inform method development. The definition of game is an indispensable part of game methodology. Though it falls outside the scope of this article to fully contend with defining games, we aim to briefly examine this issue from the standpoint of how game definitions are relevant to methodology but have been prescribing to how to steer game studies rather than how games can be designed more consequently. Jesper Juul's "Classic Model" [34] (p. 36) synthetizes a half-century of the most relevant game definitions to arrive at a robust set of six features for broadly defining games. This is a relevant field-building step but essentially helps the study of games as opposed to the study of how to design them. A summary of how the issue of defining games has been the target of lively academic debate can be found in work by van Vught and Glas [35] (p. 210), who point out the recognized tension between defining games as activities and defining them as systems, before proposing a series of player heuristics for game studies. Stenros and Waern [36] similarly go over the systems and activities debate before proposing a balance between consideration of the system and consideration of the player as the basis for defining games, in that neither the system nor the player can meaningfully define games; rather, a particular game is a particular relationship between system and player. Again, this is relevant for methodological development in game design, but the lively debate on game definitions is aimed at studying games, including their design, rather than systematizing how to design original games. Neves et al. [37] propose a cybernetic model for understanding agency in games as communication that necessitates joint consideration of system and player, following certain re-definitions of the concept of agency in games.

Game design methodology is difficult to disentangle from the study of games. The study of games, however, is not the same as a methodology for game design. Their purposes overlap significantly. Designing games is a legitimate research method in game studies [38], and game analysis is an indispensable feature of methods. Nevertheless, the purpose of studying games is understanding games, play, and their ramifications such as they are, more than prescribing how games should be designed, which is more properly the purview of game design methods. The study of games is relevant for game design methodology but is not sufficient on its own for supplying method; at best, it can frame design efforts, falling short of helping the systematization of design knowledge. As examined by Kultima [31], "game design" is mentioned often in games scholarship, but design research in games is relatively underdeveloped, while at the same time, most game design books focus on taxonomies of design elements and narrow practical advice over the systematic examination of the creative design process. Overall, games scholarship is still somewhat estranged from game design practice. Although this does not reflect what games research and game science truly entail, as found by related work mentioned in Section 2 of this paper, and has already begun to change, the benefits to practice and game design teaching have yet to fully materialize, and the longstanding consequences of this impasse 
remain. Contributions such as those intended by our paper can help materialize these benefits and finish the process of overcoming the impasse between games scholarship and game design practice.

\subsection{Game Design Books}

The estrangement between games scholarship and the games industry is reflected in how a rough distinction can be made between game design books by academics and "practical" game design books by practitioners with industry experience. Though this distinction was eventually blurred as games academia gained a degree of consolidation, there was a difference in goals for academic books and practical books. Academic books have been more concerned with scholarly rigor, have tended to more ostensibly focus on the study of games over game design methodology, and usually did not achieve the same popularity as practical books. Practical books have at times achieved a degree of popularity, were comparatively not as concerned with rigor and were purportedly about game design methodology. The book by Salen and Zimmerman [2] is an example of a more practical book where the authors are concerned with rigor and present themselves as scholars as much as practitioners.

In seemingly providing game design methods and in being known to a fair share of practitioners, practical books would appear to have solved the widespread adoption issue for game methods. The issue is that these books are more about the study of games [30], defining games, taxonomies of games, and taxonomies of design elements, than they are about method, providing conceptual design tools and a basis for systematizing the accumulation of design knowledge. Game definitions and taxonomies are a needed first step in methodology, but these are never settled upon. Typically, each new game design book never fully invests in the second step of providing method following the first step of defining games and game design concepts. Each book feels obliged to re-litigate the question of what are the ingredients of game design because these definitions remain fragmentary and still open and cannot dedicate themselves to method. This is due to the field-building struggles that game design and the study of games have faced over 40 years. Originally, the study of games was indistinguishable from the study of game design. Only as the medium of games became better-established did the possibility that game methodology can have different goals than the study of games become apparent.

The first recognizable published game design book is Chris Crawford's The Art of Computer Game Design, published in 1982 [4]. At this point in the history of game design methodology, it was indistinguishable from the study of games. Though the study of games, namely traditional games, analog games, and sports, predates digital games becoming an industry, game studies researchers only claimed it a field of study in its own right around the early 2000s [33]. Crawford's book defines games and presents a taxonomy of games before describing a series of steps for the game development process. This matter is more properly studying games as opposed to game design methodology. Crawford's book goes on to devote a single chapter to describing actual design techniques, such as triangularity. This is seemingly more in line with supplying method, but even this chapter is interspersed with descriptions of aspects of certain games, such as asymmetry, where this is persisting in taxonomy, or generic recommendations, such as making the difficulty curve smooth, or engendering a perception of "winnability". The book closes with an account of the development process for a specific game undertaken by the author. In 1982, the distinction between game design and game development was still blurred.

Crawford's book typifies the relationship with game design methods of subsequent game design books, combining self-reflection by game design practitioners with industry experience, defining games, taxonomies of games, and taxonomies of design elements, but ultimately studying games over supplying method. Examples include the books by Salen and Zimmerman [2], by Schell [39], by Fullerton [12], and by Adams and Rollings [40]. The book by Adams and Rollings, Fundamentals of Game Design, had a follow-up in the 2012 book by Adams and Dormans [41] titled Game Mechanics: Advanced Game Design. This 
book still starts with the study of games and definitions and taxonomies, albeit as a more formalized, deeper discussion of mechanics, emergence, and game economies, more or less building on the previous book's handling of the fundamentals. Because the previous book had already tackled the basics, this left more room to deal with more advanced concepts and even method. This is somewhat atypical in game design books, which have tended to spend too much of their page counts reinventing basic definitions to have room for formal method. Adams and Dormans' book then introduces the machinations system of game design notation and describes its use, and provides a starting set of design patterns, encouraging readers to use the pattern format, notation, and an interactive diagraming tool to build more patterns. This is a notable step towards core methodology in the context of game design books but failed to achieve the needed adoption to solve the method issue in game design.

\subsection{Notations and Tools}

The introduction over the past 20 years of systems for game design notation, software tools for game design annotation, and schematization, including AI-driven tools, would seem to suggest the impeding resolution to game design's method adoption problem. While notations and tools are highly relevant to methodology, they are not primarily a design method, much like understanding and employing musical notation is not the same as composing music while building on well-known systems, such as musical scales. Notations and tools organize the application of game design knowledge to game projects, but that knowledge has to come from somewhere. This design knowledge can be informally generated by the game designer through raw iteration and conventions. This has largely been the case for game design practice over the last few decades [11] and significantly limits the advancement of design knowledge. Alternatively, the designer can be supported by a discipline-wide basis for systematizing design knowledge, which is the focus of this paper. Notations are not incompatible with such a basis. Adams and Dormans [41] created a collection of game design patterns where the systematization of design knowledge works through the machinations game design notation [41]. Notations and tools can shape and aid the generation of design knowledge.

Machinations is both a notation system and a schematization tool. Dormans introduced it as a notation system in academic publications starting in 2009 [42]. Between 2009 and 2012, Dormans developed it as a dynamic diagramming application for game design, making it available on his personal website [43], where it could run on a browser and was available for download. The application used the concepts and visual lexicon of the notation but facilitated snapping these elements together as a dynamic diagram, which could be run with animations to simulate the inputs, outputs, and processes of systems of game design. Machinations' greatest strength is also its main methodological limitation: it has a tight scope, aligned to Dormans' research interests and research perspective, namely emergence, game economies, and games as systems. Machinations treats games as state machines, quantifying informational flow and exchanges by defining engines, sinks, generators, and similar. Though still orthogonal to implementation (to game software code, for instance) and sufficiently abstracted for applicability, Machinations has a low-level perspective of game design, circumscribed to the game as a system, and focused on game internal economies. This is reflected in how the sample patterns derived with machinations [41] tend to be for types of "engines" for converting and processing information inside the game system. Proposals for the use of Petri nets to model game designs, for instance by Araújo and Roque [44], are comparable to machinations, including in their structural, system-facing, low-level focus as a notation system. Understanding games requires a simultaneous perspective of user and system [36]. A systematization of game design knowledge that is over-reliant on the system will tend to elide this simultaneous perspective, harming its general applicability.

Besides machinations, another example of a relatively well-known game design notation system is Cook's skill atoms [45]. Where machinations somewhat abstracts the player, 
skill atoms diagram game designs as chains of learning moments, attending to player progression as the acquisition of competencies. Again, this runs up against the need to consider player and system simultaneously. Game design notations tend to only focus on a particular dimension of game design.

Annotation and diagramming tools show the same issue of specialization as notational systems, in that they can inform creativity but are not replacements for a basis for method. Neil [13] distinguishes between production and authoring tools for game development and game design tools proper, where the former is focused on achieving product-finish and the latter is focused on the unfinished nature of designs and supporting thinking. In their 2018 book Artificial Intelligence and Games [46] (pp. 176-189), Yannakis and Togelius mention a number of AI-driven game design tools by specialization in specific game genres, also noting more powerful mixed-initiative tools that are nevertheless specialized toward particular aspects of games (for instance, narratives). The same authors are also careful to note that these game design tools have gathered research interest by academics, where game development tools for automated and mixed-initiative content generation are the ones in use by the games industry.

\subsection{Frameworks}

Frameworks in game design tend to refer more to game design as an aspect of a game rather than game design as the activity of devising that aspect. This fits a larger trend of the study of games subsuming game design methodology. Theory constructs aimed at game design have tended to be more descriptive than prescriptive. This can explain the lack of progress in overcoming the method adoption problem in game design [47]. Analysis of how games work as designs is relevant for methodology, but this descriptiveness cannot happen at the cost of prescriptiveness.

MDA or Mechanics, Dynamics, Aesthetics [48] is the most well-known game design analysis framework. MDA accounts for the player, the system, and the designer but is descriptive -the aim was to provide a well-defined terminology for how game designs achieve systematic coherence. MDA can illuminate how a particular game works as a design and even allow for comparison between games, but ultimately cannot reveal the possibility space of alternative design solutions or structure these solutions as good design for the game as a whole. Frameworks such as MDA are not game design methods, as they merely show what games are and not what they can or should be.

An example of a game design framework that somewhat seeks to answer the descriptiveness-prescriptiveness imbalance is DPE, or design, play, experience [49]. This framework is based on MDA but seeks to expand it to better support the development of serious games. In the face of a lack of core methodological support in game design, the serious game sub-discipline has attempted to provide for its own methodological needs. DPE is, however, ultimately an analytical framework and reproduces the descriptiveness-prescriptiveness imbalance in formal game design thinking and game design theory constructs.

An example of a framework with a bearing on games that is design-oriented and prescriptive as opposed to solely analytical is Zagalo's engagement design model [6]. This framework seeks to provide a formal basis for ideation and invention of interaction design, going beyond existing human-computer interaction and user experience models that analyze the artifact and how users receive works. This is achieved by stepping back from the overly broad category of experience and focusing on a triadic engagement model for different widely applicable user profiles through engagement streams, where each stream specifically recommends, for instance, design focuses and interaction patterns. Though this framework holds implications for game design and is showcased in game applied cases, its focus is the broader discipline of interaction design, which applies to far more than games. The engagement design model framework does not preclude advances in core methods that are specific to game design, and the methodological and field-building needs of game design still beg for those advances. 


\section{Core Methods and Game Design Literacy}

Game design is the process of generating novel game design knowledge in the context of a particular design vision. Since games are a form of second-order design, the design of an original game is "hidden" at the start of the game design process and must be progressively uncovered by generating design knowledge about how each element of that design works as played, in relation to all the other elements. Design knowledge is generated for one element based on knowledge generated for other elements. This essentially describes iteration and playtesting as established practices in game design. Typically, design knowledge in this process is generated solely within the process itself while complemented by the experience of the development team, genre conventions, and analytics. This severely limits the possibilities for advancing design knowledge. Game designers have to "reinvent the wheel" to some extent in each project and are forced into piecemeal innovation. We describe as core methods the part of game design methodology that deals with supporting the generation of design knowledge both by bringing preceding knowledge to bear on a project in a more systematic, applicable way and by supporting the generation of new knowledge within the project. Game design patterns are the main example of a core method. Crucially, the ability of a core method to bring systematized design knowledge from beyond a particular game design process to bear on that process requires widespread adoption or at least broad recognition. Core methods need to be living bodies of method, and this applies to game design patterns. In this paper, we propose that the solution is not a common language across the entire discipline of game design, as recommended by the early proponents of game design patterns $[17,18]$, but a common criterion for recognizing game design to help build languages.

\subsection{Game Design Patterns}

As mentioned in the Introduction to this paper, proposals for a general formal game design vocabulary gathered the most interest between 1999 and 2006, at which point a specialization of method occurred as the widespread adoption required by these methods to perform their role never materialized. In 2002, Kremeier [17] highlighted the methodological qualities of design patterns in fields such as architecture, software, and interaction design and called for their development for game design. Previously, in 1999, Church [16] had proposed formal vocabularies in much the same vein as patterns while lacking some of their sophistication, by arguing for the need for a formal, abstract means of systematizing design knowledge, outlining a format for discovery and encapsulation of these elements of design knowledge, and offering a few sample-elements in this approach. Björk and Holopainen's seminal game design pattern language proposal came along in 2003 [18] and continued to be developed as a complete language [19]. This language did not meet with widespread practitioner adoption, it failed to become a living language of game design.

The first formal design pattern language was introduced by Alexander et al. [50] to formalize and abstract the quality of good architecture in the relationship between people and buildings as reusable design solutions that need not solve the same problem "in the same way twice" (p. 10), that is, generating design knowledge both from outside and inside the design process. Pattern languages are comprised of pattern templates, individual patterns, and the relationship between them. The template dictates which information needs to be entered to add a pattern to the language. This typically includes a name for the pattern and a short description, a formulation of the context and problem the pattern solves, a description of the solution in the pattern, and the relationship between the pattern and other patterns in the language, such as hierarchies, alternatives, or incompatibilities. The design of the template has to provide two of the greatest strengths of patterns. The first strength is vast applicability while being adaptable to specific situations. The second strength is the ability to add new patterns to the language, which helps deliver on the first strength. Pattern languages support the design process not only at the level of individual patterns but also at the level of relationships between patterns, particularly hierarchies and multiple levels of abstraction. 


\subsection{Game Design Pattern Learning}

Though Björk and Holopainen taught workshops on pattern creation and delved into the issue of teaching patterns [51] as well as continuing to expand their pattern language, their focus was arguably on achieving a pattern collection that could account for game design as a whole. In what is one of the more promising efforts in making game design patterns work since their introduction, Barney [52] takes a step back from the idea of a common vocabulary and focuses on a common way of building vocabularies, a common basis for systematization. The textbook that introduces Barney's pattern language eschews teaching game design and instead focuses on teaching the ability to learn game design by building patterns. Pattern templates and providing pattern discovery procedures are a critical part of any pattern language, but Barney goes further in defining a multi-part program of exercises for readers to develop their ability to create their own languages as fitting their design needs. This is essentially a way of tackling the pattern adoption problem by steps. Rather than proposing that all game designers immediately adhere to one integrated pattern language, Barney takes a pedagogical approach, teaching pattern creation and encouraging game designers to create their own languages. Barney emphatically seeks to deliver on the power of "creating a Pattern Language" over "having a Pattern Language" [52] (p. 49). Achieving functional completeness is treated as premature given the current state of game design methodology, and the adoption problem for core game design methods is tackled by getting game designers to use the core method, at all, rather than one particular language. Barney's focus on pedagogy is broadly compatible with our own solution to the method adoption problem while following a different approach.

\subsection{Game Design Literacy}

We propose a novel practical foundation of games literacy as a first step in solving the method adoption problem of game design. The longstanding legitimacy and fieldbuilding issues of game design [27] continue to create problems for game design practice and harming the advancement of methodology. The study of games has confused the methodology issue. Lack of a common basis for game design literacy continues to harm working game designers, where scholarly literacy still fails to meet this need.

In the industry, game designers can feel that their contributions to a game development project are invisible [53] and constantly at risk of being subsumed by, for instance, game metrics [54]. Game audiences relate to their experience of the game and to particular moments that emerge in play but find it harder to trace this to game design than to technological features such as procedural generation and artificial intelligence, or art direction, graphic fidelity, thematic aspects, and the game narrative. A game designer working on a serious game with specialists in other fields may find that these specialists lack an even cursory understanding of what it takes for the interactive work under development to be a game to any meaningful extent, due to lack of basic game design literacy and due to the still insular nature of basic game design research. Depending on their field, these specialists will either be preoccupied with the player or the system. The game designer can scarcely afford to retrace the entire debate on defining games in game studies to have a basis to collaborate with the specialists for other fields. The debate needs to be "packaged" into a working principle that can allow game design methodology to gain traction.

Audiences tend to be more directly exposed to the game design process through development practices such as early access and open game betas, where development studios publish the game in a relatively finished state and solicit player community feedback and updates to online games. This means that game audiences only encounter game designs when they are already in the latter stages of the game design process. The scope of design decisions tends to narrow throughout the game design process. Deeper conceptual changes that define the game take place earlier in the iterative process, and smaller-scope adjustments to particular variables take place later in the process [12] (p. 278). Because audiences are only allowed to perceive game design at these later stages, in comparing changes in variables between game updates or balancing patches, they end up with a 
narrow conception of game design. There has been some progress over the last decade in drawing the attention of audiences to game design through the democratization of game production tools and amateur publishing such as itch.io, and online game jams. Web series such as Game Maker's Toolkit [55] have attempted to analyze game design for the game-playing public. Nevertheless, game design remains a difficult-to-pin-down quality for game audiences.

As a field, game studies are unable to present a solid foundation for a basic literacy of game design. This is partly due to the vicious cycle of methodologies not developing due to lack of adoption and partly due to the partial impasse regarding game design in academia. In this paper, we hold that the issue is that formal thinking on game design has been dominated by descriptiveness. This can be attributed to various field-building and legitimacy issues surrounding games [27]. We propose a new basis for game design literacy that enforces prescriptiveness over descriptiveness as a condition for more prescriptive, successful core methods. The basis is, summarily, that a game is chiefly defined by how it affords players multiple ways of playing meaningfully but also affords those players reasons, in the context of play, to not play the same way all the time. The player chooses the points at which to modify her play based on the dynamic nature of game states as well as her own preferences. Play becomes an act of owning particular conduct in play, and game design work needs to support this and make it meaningful. As a basis for game design literacy, this criterion means that games are recognized as such based on whether they clearly present this dilemma. This provides a direction for design work. For instance, serious game development often faces the issue of whether or not game qualities are being effectively developed or if the "serious game" under development falls short of being a game and amounts instead to a series of exercises surrounding desired instrumental (from a clinical or educational standpoint) outcomes. The dilemma could provide a clear criterion for this distinction, as well as facilitate communication between team members from different disciplines in developing the serious game. For training game designers, the dilemma provides an aim for iteration and testing practices being taught, a logic to structural taxonomies of game elements being taught, and a criterion for assessing student-designed games.

\section{Defining Games for Method}

Joris Dormans [47] attributes the lack of widespread adoption of a game design method to lack of prescriptivity, where successive method proposals originated with game studies and so took a neutral stance of describing game designs rather than making the prescriptive judgment of what constitutes good game design. This harmed method in breaking out of scholarship and going into practice in the design of new games.

The game design principle proposed by this paper is an attempt to fulfill the role of what Dormans calls "a clear formulation of what constitutes quality in games", an "equivalent notion to the notion of object-orientation in software design patterns" [47] (p. 2), the lack of which Dormans argues is responsible for the adoption problem of game design methods. Mukherjee frames the contribution of object-oriented programming (OOP) to software design as dispensing with an artificial division "between the non-technical element and the technical code" so that the quality of designs becomes a kind of autonomy for the object being designed, in which every "object has within itself all that it needs to go about its business" [56] (p. 13). OOP, therefore, accounts for how different elements of the functional whole act upon each other. This paper aims to propose a design principle that can serve this purpose for game design. Rather than the game designer considering effects on the player and processes in the system separately, even while attending to their interrelation, the designer can instead consider this kind of autonomy as a defining quality for the artifact being designed, where player and game system are being tackled simultaneously. This gives the designer something concrete to design for, or at least a needed supplement to how she situates her practice: a concrete notion of the quality of being game-like in games. 
It should be noted that Mukherjee raises the example of OOP as part of highlighting how the existing notion of supplementarity applies to games, which in turn is part of a larger argument for disregarding artificial distinctions between player, story, and game, which introduces a book's worth of exploration of a framework to re-inform and rethink "game studies perspectives" [56] (pp. 20-21), and to overcome "watertight categorizations that mark out "player studies" from "game studies" [56] (p. 218). This paper also aims to strengthen alternatives to certain well-established game studies perspectives, although with a more modest scope and reach than Mukherjee's efforts, and leaving out issues of story.

We follow Dormans in this assertion of the need for prescriptivity in method, but further argue that this requires a "packaging" of basic game design research as a foundation of a more practical basic game design literacy. Defining the basis for a game design method is an exercise in "designing design", in that spirit, it should be "good enough" as opposed to "perfect".

One way of looking at this "packaged" basic literacy of a definition of game is that it needs to be something that can easily be explained and put to use as a working principle. Teaching game design tends to be done purely through practice, with an experienced game designer guiding small groups of students in real game development projects while acquainting them with the epistemic frame of the community of practice. An example of this kind of teaching is the game design practicum described by Nash and Schafer [57]. Lack of traction for game methodology and basic game design research means that this is done experientially for the most part, with limited support from theory frames apart from rules of thumb or informal accounts from even more experienced game designers. In this situation, what can game design students be referred to that is effective, or "good enough" in guiding their practice? For the game designer working with specialists from other fields on a serious game, what can summarize the requirements for meaningfully working on the game aspect of that serious game project?

The "packaged" definition of "game" should be compatible with the meaningful definition attained by game studies, that games cannot be considered either as system or as player, but that every game is a particular player-system relationship, as argued by Stenros and Waern [36]. This definition of games is compatible with work on agency as a quality of game designs, including models oriented toward design work [37].

We propose the game design principle that games need to offer dynamic analog dilemmas, as forming a "good enough", "packaged" definition of games for informing game design methodology following the requirements outlined in this article. A consequence of this elementary principle is that games need to allow the player to express a conduct in play. The principle draws from the simultaneous player-system view but is prescriptive and is meant to also help teach game design and help collaboration between game design and other disciplines. The principle strongly emphasizes games as second-order designs. A game that is designed toward embodying this principle will be emphasizing the more meaningful characteristics of games. The pricpline constitutes a stance on what games should be. The idea is for game design methodologies to orient design work in new games toward this principle.

The concept of a dynamic analog dilemma as enabling player conducts was devised by one of the authors of this paper, Pedro Neves, as a prescriptive frame to assist in designing the curriculum for a first-year undergraduate game design course in the videogames degree at Lusófona University in Portugal between February 2019 and July 2021. The dilemma helped structure the games taxonomy taught to students (adapted from multiple sources by the author) but, more importantly, it was used to structure learning of game prototyping and testing procedures and to define the student assignment of creating an original game. The dilemma provided students something concrete to strive for with original game creation, and relative success in achieving and validating the dilemma was used to evaluate the resulting games. Informal observation of learning practices and student progression suggests that the dynamic analog dilemma provides a direction for 
students to iterate on their projects, helping progress between iterations. Communication with students was helped overall, with tutoring, feedback, and assessment being organized around a single concrete foundation as opposed to, for instance, a set of disparate rubrics pertaining to the artistic merits of student games. Learning with the dilemma seems to have contributed to student outcomes in a subsequent, more advanced game design course in terms of the ability of students to frame and analyze their own projects.

Our principle is inspired by the taxonomy of game dynamics as proposed by Braithwaite and Schreiber [58]. Though this taxonomy is part of the tradition of game design books reiterating the study of games and taxonomies of game elements while leaving little room for prescribing methods, this taxonomy phrases different game experiences as holding particular tradeoffs for the player at their cores. This makes the dynamics easy to understand and actionable. Game design work in an original game becomes an exercise in finding a new way of presenting particular tradeoffs to the player. Our approach is furthermore compatible with the model in Neves et al. [37] of the activity of play as an implicit contract for negotiating bio-costs between the design of the game's system and the player. We now present the principle as a foundation for game design literacy that we argue is more compatible with methodology and widespread adoption for methodology.

\subsection{The Dynamic Analog Dilemmas Principle}

As already mentioned at the end of Section 4.3, we propose the concept of a dynamic analog dilemma as the foundation of a "practical" game design literacy. This concept is severely limited as a descriptive frame. It empathically sacrifices descriptiveness to prescriptiveness as a means of counteracting the imbalance in formal game design thinking that has harmed core methods. This tradeoff offers better possibilities of adoption as a basic literacy of game design and for helping core methods find adoption, since it makes the presence of the dilemma more readily applicable as a criterion for judging games and guiding design. Thus, more games can be freely excluded (by overlooking descriptiveness) and designs can be steered toward the quality global minimum of a favorable ratio between design complexity (which makes it more costly for users to learn to play and keeping them apprised of their options) and range and granularity of available meaningful approaches to the game, and the complementarity between these factors. The dilemma encourages lowering complexity while increasing the range of meanings.

The presence of this dilemma becomes a basic criterion for identifying an interactive work as a game, for gauging how successful it is at being a game at a basic level, and for guiding game design work overall. Interactive works can present a player with many options, and choosing an approach to play can constitute a dilemma for the player. However, we contend that most of these dilemmas are static and discrete. Static, in this context, means that the dilemma is invariable throughout play: the options may change, but the nature of the choice remains the same. Discrete, in this context, means that player choices are essentially binary, and there is limited room for the player to position herself in a spectrum of choice in how she plays. We propose that games should be regarded as presenting a dilemma that is dynamic and analog. Dynamic in this context means that the player is continually making choices in play and the nature of these choices is highly sensitive to the game state. Analog in this context entails all meaningful player conducts in the game occupying an analog spectrum between two or more extremes of priorities in play, where these priorities relate to tradeoffs between risking access to game contents and gaining more expressive means over the game.

A consequence of the dynamic analog dilemma principle is that the meaning of game design becomes to allow the player to express a particular conduct in terms of the game, every time she plays and solely by playing. This provides a goal for game design work at the ideation stage and for all design decisions thereafter. For instance, in creating a serious game, the artifact can be steered away from being a mere exercise in achieving instrumental outcomes and toward meaningful play by checking if the design allows the 
player to express conducts and, if conducts are not available, to engage appropriate design measures toward that end.

Kuittinen and Holopainen highlight the concept of framing in design research, where the "designer frames the situation in such a way that there is a problem which can be attempted to be solved with an experimental design move" [30] (p. 3), and this provides a use for the game design principle in this paper. Game designers can use the principle to bend the design situation to be solvable. In this view, the principle exposes or at least informs a direction for progress, namely, steering the design toward the dynamic and analog qualities of the dilemma, and finding how the player can express her own conduct in terms of the game.

\subsection{Example of the Dynamic Analog Dilemma}

In view of the dynamic analog dilemma criterion, an interactive work can still be underutilizing game design and counting as a mere "exercise" even if it challenges the player to perform certain actions under certain constraints toward certain goals, promotes the development of player skills, and rewards achievement and progression. Such a game could be meeting most of the criteria for Juul's descriptive classic model [34] for defining games and still fail the prescriptive criterion of offering a dynamic, analog dilemma.

A simple example of a game that meets more descriptive definitions of game while failing the criterion of presenting a dynamic analog dilemma would be, for instance, a sidescrolling digital game where the player has to maneuver a game character across an area of alternating safe zones and dangerous zones toward an end position. The dangerous zones keep being bombarded with objects at unpredictable intervals. Figure 1 is a mockup of what the player would see on screen in this game, where the player would have to successfully scroll the screen to the right multiple times to reach the end position. The condition for losing the game is the player character taking a certain number of hits from the falling objects (tallied by the interface element on the lower left in Figure 1).

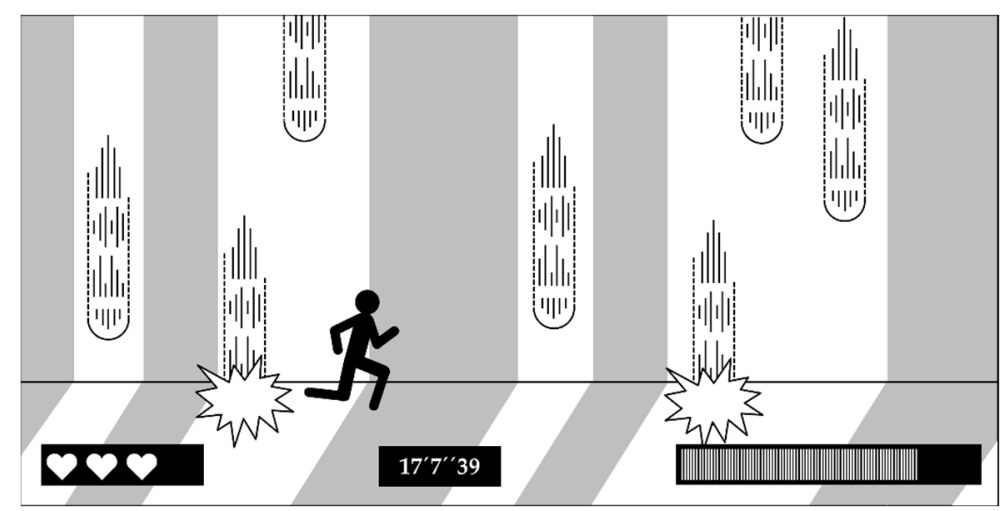

Figure 1. Mockup of the player's screen while playing the example of a game that fails to present a dynamic analog dilemma. The screen would scroll as the player moves. The mockup shows the human figure controlled by the player, safe zones in gray, dangerous zones in white, falling objects, and three guide-user interface elements.

The challenge for the player is in timing when the character moves between safe zones or even reversing direction temporarily to dodge a falling object. The addition of a countdown game-timer (bottom of Figure 1) would allow a score to be attributed to the player in case of successfully reaching the end position, the faster the player reaches the position, the better the score. The player would be choosing between playing it safe and getting a lower score or taking risks and perhaps not reaching the end position.

As a game design, this game is no more than a rote exercise in dexterity. Even procedural generation of the gameworld (alternation of safe zones and dangerous zones) and randomization of the falling objects would do relatively little to make playing this game more than a training exercise in using its controls to best effect. 
In the example of a game of safe zones and dangerous zones above, the player's ability to move her character could be tied to an explicit in-game resource, something like the well-worn game concept of a stamina bar (lower right in Figure 1), where player movement depletes the resource between a maximum and a minimum, and the resource replenishes automatically over time as long as the player character is standing on a safe zone (Figure 2a). Trying to obtain a higher score by moving continuously would drain this "stamina" resource completely. This might leave the player unable to move the character while still in a dangerous zone. This forces the player to alternate between wasting time and final score waiting for the resource to self-replenish or take on increased risks of losing. The game has become more involved but still fails to meet the criterion of a dynamic analog dilemma. The player is faced with a dilemma between wasting score and taking risks, but this dilemma is static and discrete, it is relatively insensitive to game design decisions regarding the size of the zones, the frequency and unpredictability of falling objects, how many hits the player character can take before the player loses, the player character's movement speed, or maximum value and rate of depletion for the stamina bar. Regardless of the design of all of these factors, and as long as the resulting challenge in play could be overcome but still not trivial, the player would be simply adapting to the factors. There would be an optimal way of playing, like in an exercise. The dilemma is not dynamic because it is not shifting with the changes in the game state or even with changes to the game's design; the player is invariably waiting to replenish the minimum, optimal amount of stamina for safe traversal. The dilemma is not analog because it only applies at the point of victory or defeat for the player, rather than being continuously re-applied in play.

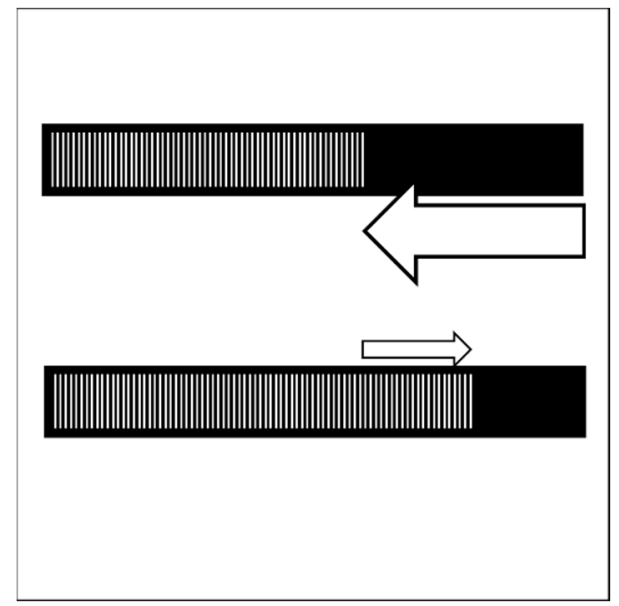

(a)

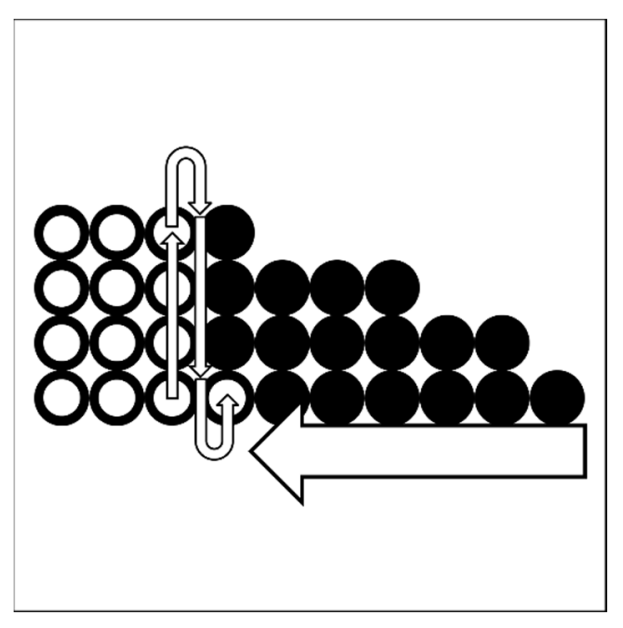

(b)

Figure 2. Mockups of the interface elements that show the player the state of the stamina variable before and after the game starts presenting a dynamic analog dilemma: (a) fixed rate of depletion and replenishment; (b) spending one unit of the in-game stamina resource depletes an entire row, right to left, but replenishment of a unit only occurs after all cells in a row are refilled, bottom to top.

The example game fails to meet the criterion of offering a dynamic analog dilemma if its rates for depletion and self-replenishment of the stamina resource remain fixed. In this scenario the player always regenerates stamina at the same rate, regardless of how much of the resource they have left (Figure 2a). One way the example game could start meeting the criterion would be simply by letting the rate of depletion of the stamina resource remain fixed, but changing the rate of replenishment to follow a geometric progression where the lower the value of the stamina resource, the slower the rate of regeneration, as shown on Figure 2b.

Before this change, there would be an optimal way of playing the game relative to whatever constraints apply to play; after the change, there would be an analog spectrum of player conducts that is highly sensitive to shifting variables in the game state. Figure 3 is a 
mockup of what the player would see on screen in the example game with the behavior of the stamina resource causing the game to present a dynamic analog dilemma, with the interface element in Figure $2 \mathrm{~b}$ visible on the lower right.

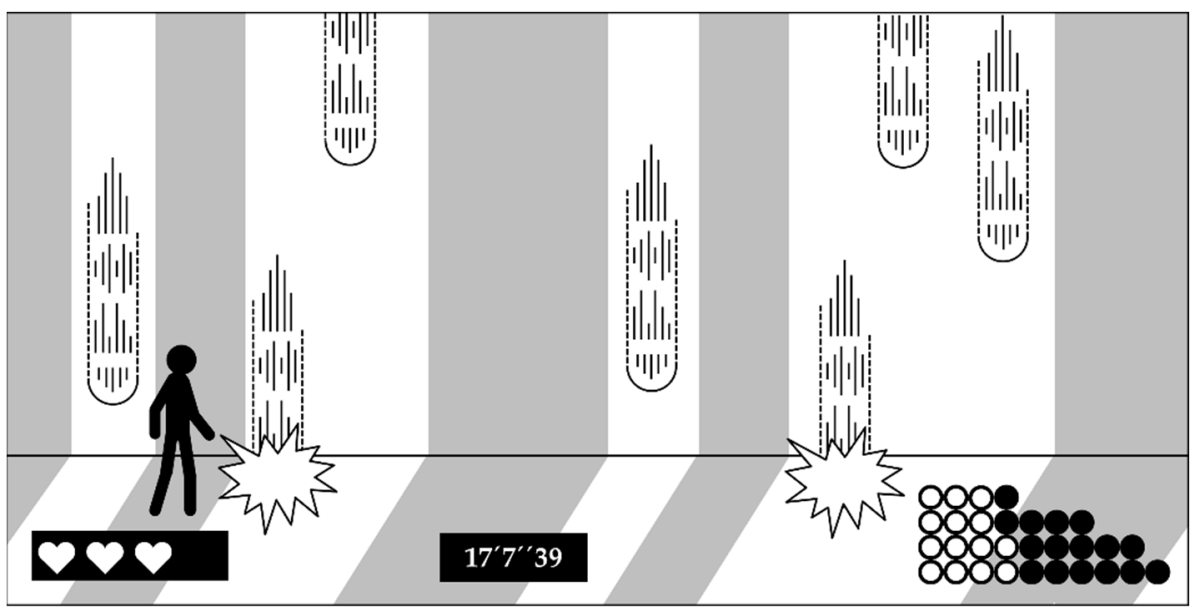

Figure 3. Mockup of the player's screen while playing the example of a game that successfully presents a dynamic analog dilemma through the behavior of the stamina in-game resource.

With a scaling rate of regeneration for movement capacity ("stamina"), the player would be facing a different choice every time they decided to move or stand still. Rather than having to work out the "correct" sequence of moving forward and waiting given constraints, the player could conceivably be just as successful with a conduct of picking the right moments to spend stamina in long bursts or with a conduct of moving in short bursts. Long bursts would be profitable in allowing multiple safe and danger zones to be traversed at once but would leave less of a margin for reversing direction to "dodge" falling objects. The player would have to choose the best moment to start moving, which fits with the need to wait longer for stamina to replenish. With short bursts, the player is not required to be as careful with choosing when to start moving, as stopping at every safe zone lets stamina regenerate quickly and affords a margin for dodges. Indeed, making short bursts profitable requires the player to hesitate far less in resuming forward motion. The long bursts and short bursts are not a static binary of choices but rather different balances of priorities for player approaches as afforded and motivated by the game.

\section{Conclusions}

Game design methodology needs to value different expressions in game design differently: if not as "good" and "bad" design, then as more "core", or game-like, or less "core". This lets methodology support game designers in systematically defining how "game-like" they intend their games to be and anticipate the ramifications of being more or less game-like. Designers would then be in a better position to make tradeoffs and decide how to secure global minimums of being "game-like" in their designs. The principle for defining games we propose for supporting game design methodologies is meant as a goal for game design work. We argue that design decisions during a game design process should take this principle into account. As a general rule, design decisions made during a game's conception and development should orient the game's design toward this principle of a dynamic analog dilemma giving meaning to player conducts. Decisions that move the game away from the principle should be made with good reason. Beyond ordinary industry use, such as designing commercial games for entertainment, the principle can be used to guide game design teaching and serious game design. Student projects can be evaluated on the basis of how they use original solutions to uphold the principle, and the game-like qualities of serious games can be developed by orienting them toward the principle. The principle presents a number of severe limitations, which matter more from a 
descriptive rather than prescriptive standpoint, and which do not necessarily compromise the usefulness of the principle for helping design work.

The principle would seem to exclude an extensive number of games from being regarded as legitimate designs. Adventure games for instance often do not offer explicit lose conditions, and more recently, games in the walking simulator genre typically eschew any explicit resistance of the game to the player altogether. The principle also seems to erase the possibilities of using games for artistic expression and for social and cultural criticism by making instrumental play the indispensable core of game design work. Instrumental play (playing for goals and efficiency) has been criticized as eliding much of the significance in play through an excessive focus on procedurality [59]. However, it should be noted that the principle being prescriptive rather than descriptive means that design visions for games that deviate from the principle are not being excluded and are rather being simply highlighted as a subversive creative stance. Currently, the relevance of these visions might be lost in the fragmentary nature of game design knowledge. With the principle being used as a "good enough" basic understanding of games, designers would be taking responsibility more fully for these deviations and gauging their implications for game design and the relationship with the player more systematically. If the principle was descriptive, it would effectively be excluding diversity in game design and constraining creativity. Because the principle is prescriptive however it merely defines the expressive territory of games as a continuum, where there are expressions that are more central to this territory and other expressions that are more peripheral. The issue of whether a certain kind of game is more or less central in the realm of games can be left to the appropriate sub-domains of game studies; ours is a working distinction for purposes of encouraging practical adoption of game design methodology.

It should also be noted that the principle is foundational to games, which opens up a great deal of flexibility in its implementation. Originality in game design can be phrased as original implementations of the principle. For instance, in the case of narratively driven games, the principle implies that the player collapses narrative possibilities as she plays. In this view, the dynamic and analog dilemma means that the player is gambling against the loss of narrative possibilities as the narrative actualizes and collapses through play. This is consistent with certain conceptions of agency particularly relating to narratives such as Adams' [60] (pp. 29-30). In adventure and puzzle games where there is no possibility of losing the game, the player is not gambling her continued access to play. This together with the lack of changing variables for representing the player's increased power over the game state would seem to place these games out of the reach of the dynamic analog dilemma. However, by taking a step back and considering the player's investment in the game from a cybernetic, bio-costs perspective [37], the dynamic analog dilemma for the player becomes a question of gambling her attentional resources. The dilemma is between having to focus on a given hypothesis for a solution path to a puzzle but not so much that the player is unable to consider alternate hypotheses.

Author Contributions: Conceptualization, P.P.N. and N.Z.; investigation, P.P.N. and N.Z.; WritingOriginal draft, P.P.N.; Writing-Review and editing, N.Z. All authors have read and agreed to the published version of the manuscript.

Funding: This research received no external funding.

Conflicts of Interest: The authors declare no conflict of interest.

\section{References}

1. Zagalo, N. Multimodality and Expressivity in Videogames. OBS 2019, 13, 86-101. [CrossRef]

2. Salen, K.; Zimmerman, E. Rules of Play: Game Design Fundamentals; MIT Press: Cambridge, MA, USA, 2003; ISBN 978-0-262-24045-1.

3. Nacke, L.E.; Bateman, C.; Mandryk, R.L. BrainHex: A Neurobiological Gamer Typology Survey. Entertain. Comput. 2014, 5, 55-62. [CrossRef]

4. Crawford, C. The Art of Computer Game Design; Osborne/McGraw-Hill: Berkeley, CA, USA, 1984; ISBN 978-0-88134-117-1.

5. Cairns, P. Can Games Be More than Fun? In Funology 2; Springer: Cham, Switzerland, 2018; pp. 33-46. 
6. Zagalo, N. Engagement Design: Designing for Interaction Motivations; Human-Computer Interaction Series; Springer International Publishing: Cham, Switzerland, 2020; ISBN 978-3-030-37084-8.

7. Miller, P. Top 10 Pitfalls Using Scrum Methodology for Video Game Development. Gamasutra 2008. Available online: https: / /www.gamasutra.com/view/feature/132121/top_10_pitfalls_using_scrum_.php?print=1 (accessed on 15 July 2021).

8. Aleem, S.; Capretz, L.F.; Ahmed, F. Game Development Software Engineering Process Life Cycle: A Systematic Review. J. Softw. Eng. Res. Dev. 2016, 4, 6. [CrossRef]

9. Hodent, C. The Gamer's Brain: How Neuroscience and UX Can Impact Video Game Design; CRC Press: Boca Raton, FL, USA, 2018; ISBN 978-1-4987-7550-2.

10. Drachen, A.; Mirza-Babaei, P.; Nacke, L.E. (Eds.) Games User Research, 1st ed.; Oxford University Press: Oxford, UK; New York, NY, USA, 2018; ISBN 978-0-19-879484-4.

11. Neil, K. How We Design Games Now and Why. In Critical Hits: An Indie Gaming Anthology; Liberties Press Limited: Dublin, Ireland, 2016.

12. Fullerton, T.; Swain, C.; Hoffman, S. Game Design Workshop: A Playcentric Approach to Creating Innovative Games, 2nd ed.; Elsevier: Amsterdam, The Netherlands; Morgan Kaufmann: Boston, MA, USA, 2008; ISBN 978-0-240-80974-8.

13. Neil, K. Game Design Tools-For When Spreadsheets and Flowcharts Aren't Enough. In Proceedings of the GDC 17, San Francisco, CA, USA, 27 February-3 March 2017; Available online: https:/ / www.youtube.com/watch?v=XPPtLNkVPWY (accessed on 15 July 2021).

14. Wilson, D.W.; Jenkins, J.; Twyman, N.; Jensen, M.; Valacich, J.; Dunbar, N.; Wilson, S.; Miller, C.; Adame, B.; Lee, Y.-H.; et al. Serious Games: An Evaluation Framework and Case Study. In Proceedings of the 2016 49th Hawaii International Conference on System Sciences (HICSS), Kauai, HI, USA, 5-8 January 2016; pp. 638-647.

15. Cote, A.C.; Harris, B.C. The Cruel Optimism of "Good Crunch": How Game Industry Discourses Perpetuate Unsustainable Labor Practices. New Media Soc. 2021. Available online: https:/ / journals.sagepub.com/doi/10.1177/14614448211014213 (accessed on 15 July 2021). [CrossRef]

16. Church, D. Formal Abstract Design Tools. Gamasutra 1999. Available online: https://www.gamasutra.com/view/feature/1317 64/formal_abstract_design_tools.php?print=1 (accessed on 15 July 2021).

17. Kreimeier, B. The Case for Game Design Patterns. Gamasutra 2002. Available online: https://www.gamasutra.com/view/ feature/132649/the_case_for_game_design_patterns.php?print=1 (accessed on 15 July 2021).

18. Kreimeier, B.; Holopainen, J.; Björk, S. Game Design Patterns. In Proceedings of the Game Developers Conference 2003, San Jose, CA, USA, 4-8 March 2003.

19. Björk, S.; Holopainen, J. Patterns in Game Design, 1st ed.; Charles River Media Game Development Series; Charles River Media: Hingham, MA, USA, 2005; ISBN 978-1-58450-354-5.

20. Lewis, C.; Wardrip-Fruin, N.; Whitehead, J. Motivational Game Design Patterns of 'ville Games. In Proceedings of the International Conference on the Foundations of Digital Games, Raleigh, NC, USA, 29 May-1 June 2012; pp. 172-179.

21. Hullett, K.; Whitehead, J. Design Patterns in FPS Levels. In Proceedings of the Fifth International Conference on the Foundations of Digital Games, Monterey, CA, USA, 19-21 June 2010; pp. 78-85.

22. Alves, V.; Roque, L. Design Patterns in Games: The Case for Sound Design. In Proceedings of the DPG 13: Second Workshop on Design Patterns in Games, Chania, Greece, 14-17 May 2013.

23. Marne, B.; Wisdom, J.; Huynh-Kim-Bang, B.; Labat, J.-M. The Six Facets of Serious Game Design: A Methodology Enhanced by Our Design Pattern Library. In Proceedings of the European Conference on Technology Enhanced Learning; Springer: Berlin/Heidelberg, Germany, 2012; pp. 208-221.

24. Junaidi, J.; Julianto, A.; Anwar, N.; Safrizal, S.; Spits Warnars, H.L.H.; Hashimoto, K. Perfecting A Video Game with Game Metrics. TELKOMNIKA 2018, 16, 1324. [CrossRef]

25. Sarkar, A.; Cooper, S. Towards Game Design via Creative Machine Learning (GDCML). In Proceedings of the 2020 IEEE Conference on Games (CoG), Osaka, Japan, 24-27 August 2020; pp. 744-751.

26. McEntee, C. Rational Design: The Core of Rayman Origins. Gamasutra 2012. Available online: https://www.gamasutra.com/ view / feature/167214/rational_design_the_core_of_php (accessed on 15 July 2021).

27. Deterding, S. The Pyrrhic Victory of Game Studies: Assessing the Past, Present, and Future of Interdisciplinary Game Research. Games Cult. 2017, 12, 521-543. [CrossRef]

28. Klabbers, J.H. On the Architecture of Game Science. Simul. Gaming 2018, 49, 207-245. [CrossRef]

29. Cardona-Rivera, R. Foundations of a Computational Science of Game Design: Abstractions and Tradeoffs. In Proceedings of the AAAI Conference on Artificial Intelligence and Interactive Digital Entertainment, online, 19-23 October 2020; pp. 167-174.

30. Kuitinnen, J.; Holopainen, H. Some Notes on the Nature of Game Design. In Proceedings of the 2009 DiGRA International Conference: Breaking New Ground: Innovation in Games, Play, Practice and Theory, West London, UK, 1-4 September 2009.

31. Kultima, A. Game Design Research. In Proceedings of the 19th International Academic Mindtrek Conference, Tampere, Finland, 22-24 September 2015; pp. 18-25.

32. Perez, E. (Game) Design Methods in Game Studies. In Proceedings of the 2018 DiGRA International Conference: The Game is the Message, DiGRA, Turin, Italy, 25-28 July 2018.

33. Aarseth, E. Computer Game Studies, Year One. Game Stud. 2001, 1, 1-15. 
34. Juul, J. Half-Real: Video Games between Real Rules and Fictional Worlds; MIT-Press: Cambridge, MA, USA; London, UK, 2011; ISBN 978-0-262-10110-3.

35. Van Vught, J.; Glas, R. Considering Play: From Method to Analysis. Trans. Digit. Games Res. Assoc. 2018, 4, 1-19. [CrossRef]

36. Stenros, J.; Waern, A. Games as Activity: Correcting the Digital Fallacy. In Videogame Studies: Concepts, Cultures and Communication; ID Press: Oxford, UK, 2011; pp. 11-22.

37. Neves, P.P.; Morgado, L.; Zagalo, N. Videogame Agency as a Bio-Costs Contract. J. Sci. Technol. Arts 2018, 10, 43-53. [CrossRef]

38. Waern, A.; Back, J. Experimental Game Design. In Game Research Methods; ETC Press: Pittsburgh, PA, USA, 2015; pp. $341-353$. ISBN 978-1-312-88473-1.

39. Schell, J. The Art of Game Design: A Book of Lenses; Elsevier: Amsterdam, The Netherlands; Morgan Kaufmann: Boston, MA, USA, 2008; ISBN 978-0-12-369496-6.

40. Adams, E.; Rollings, A. Fundamentals of Game Design, 2nd ed.; New Riders: Berkeley, CA, USA, 2010; ISBN 978-0-321-64337-7.

41. Adams, E.; Dormans, J. Game Mechanics: Advanced Game Design; New Riders: Berkeley, CA, USA, 2012; ISBN 978-0-321-82027-3.

42. Dormans, J. Machinations: Elemental Feedback Structures for Game Design. In Proceedings of the GAMEON-NA Conference, Atlanta, GA, USA, 26-28 August 2009; Volume 20, pp. 33-40.

43. Dormans, J. Machinations: Game Feedback Diagrams. Available online: https://web.archive.org/web/20121003130005/http: / / www.jorisdormans.nl/machinations / (accessed on 16 July 2021).

44. Araújo, M.; Roque, L. Modeling Games with Petri Nets. In Proceedings of the DiGRA 2009—Breaking New Ground: Innovation in Games, Play, Practice and Theory, West London, UK, 1-4 September 2009.

45. Cook, D. The Chemistry of Game Design. Gamasutra 2007. Available online: https://www.gamasutra.com/view/feature/1524 /the_chemistry_of_game_design.php?print=1 (accessed on 15 July 2021).

46. Yannakakis, G.N.; Togelius, J. Artificial Intelligence and Games; Springer: Berlin/Heidelberg, Germany; New York, NY, USA, 2018; ISBN 978-3-319-63518-7.

47. Dormans, J. Making Design Patterns Work. In Proceedings of the DPG 13: Second Workshop on Design Patterns in Games, Chania, Greece, 14-17 May 2013.

48. Hunicke, R.; LeBlanc, M.; Zubek, R. MDA: A Formal Approach to Game Design and Game Research. In Proceedings of the AAAI Workshop on Challenges in Game AI, San Jose, CA, USA, 25-26 July 2004; Volume 4, p. 1722.

49. Winn, B.M. The design, play, and experience framework. In Handbook of Research on Effective Electronic Gaming in Education; IGI Global: Hershey, PA, USA, 2009; pp. 1010-1024.

50. Alexander, C.; Ishikawa, S.; Silverstein, M.; Jacobson, M.; Fiksdahl-King, I.; Angel, S. A Pattern Language: Towns, Buildings, Construction; Oxford University Press: New York, NY, USA, 1977; ISBN 978-0-19-501919-3.

51. Holopainen, J.; Kuittinen, J.; Mayer, I.; Mastik, H. Teaching Gameplay Design Patterns. Organizing and Learning through Gaming and Simulation. In Proceedings of the ISAGA 2007, Njimegen, The Netherlands, 9-13 July 2007.

52. Barney, C. Pattern Language for Game Design, 1st ed.; CRC Press: Boca Raton, FL, USA, 2021; ISBN 978-0-367-36772-5.

53. Mandryka, A. Lifting the Designer's Curse. Gamasutra 2011. Available online: https://www.gamasutra.com/view / feature/13 4638/lifting_the_designers_curse.php?print=1 (accessed on 15 July 2021).

54. McWilliams, L. The Metrics Aren't the Message. Gamasutra 2013. Available online: https://www.gamasutra.com/view/feature/ 188197 / the_metrics_arent_the_message.php?print=1 (accessed on 15 July 2021).

55. Brown, M. Game Maker's Toolkit Web Video Series. Available online: https:/ /www.youtube.com/channel/UCqJ-Xo29CKyLTjn6 z2XwYAw?ucbcb=1 (accessed on 15 July 2021).

56. Mukherjee, S. Video Games and Storytelling: Reading Games and Playing Books; Palgrave: London, UK, 2015; ISBN 978-1-137-52505-5.

57. Nash, P.; Shaffer, D.W. Epistemic Trajectories: Mentoring in a Game Design Practicum. Instr. Sci. 2013, 41, 745-771. [CrossRef]

58. Brathwaite, B.; Schreiber, I. Challenges for Game Designers; Course Technology/Cengage Learning: Boston, MA, USA, 2009; ISBN 978-1-58450-580-8.

59. Sicart, M. Against Procedurality. Game Stud. 2011, 11, 209.

60. Adams, E.W. Resolutions to Some Problems in Interactive Storytelling. Ph.D. Thesis, University of Teesside, Middlesbrough, UK, 2013. 